\title{
Biotechnology and Food Safety
}

\begin{abstract}
Creat economic and social forces flow like a tide over half-conscious people. The wise are those who foresee the coming event and seek to shape their institutions and mold the thinking of the people in accordance with the most constructive change. The unwise are those who add nothing constructive to the process, either because of
\end{abstract} ignorance on the one hand or ignorant opposition on the other.

English economist and philosopher John Stuart M ill

Lester M. Crawford

Administrator

and

Denise L. Clarke

USDA

Food Safety and

Inspection Service

14th \& Independence

Washington, DC

20250-3700
Biotechnology will yield an expanding array of new foods, food ingredients, food additives and new processes to produce existing products. These indude bruise-free fruit, crisper celery and sweeter carrots, caffeine-free coffee beans, and low-calorie sweeteners. The Food and Drug Administration (FDA) recently approved rennet, the first biotechnologically produced enzyme approved for use in food. Much animal biotechnology research focuses on producing transgenic livestock and poultry that will utilize feed more efficiently, grow to desired slaughter weights at an earlier age, and be resistant to a variety of diseases. Farmers stand to benefit from reduced production costs, improved efficiencies, and higher quality products. Consumers will benefit becausefarmers will be able to supply leaner meat and poultry produced with a decreased dependence on vaccines, drugs and insecticides. In addition, consumers may see reduced prices at the grocery store, since farmers will produce animals of the same weight as is currently produced, but in a shorter period of time with lower production costs.

While these products and events are exciting possibilities, difficult decisions lie ahead in biotechnology. For example, bovine somatotropin (BST) which only needs to pass long-term animal health tests before re- 
To best prevent food safety problems, gov ernment, industry and consumers must acknowledge their respective responsi bilities for ensuring safe food. ceiving FDA approval, holds great promise for dairy farmers. Bovine somatotropin has been declared safe by FDA; yet it continues to be the target of food safety accusations.

Food safety is an easy target for biotechnology critics, as consumers are al ready confused and worried about food safety. A recent survey by the Food Marketing Institute reported that only 15 percent of those surveyed were "completely confident" that the food sold in grocery stores is safe. Sixty-four percent of consumers said they were "mostly confident" about supermarket food.

A recent Michigan Department of Agriculture survey indicated consumer confidence in food had declined and that food safety depended upon government inspection and regulation. Those surveyed said increased food product testing was the single best method to improve food safety. From the perspective of the FDA this may appear to bea positive finding, however, it gives rise to a concern that some consumers feel that more sampling and testing is the single key to safer food.

Sampling and testing are important for detecting potential violations and problems, but detection is not theoptimal way to ensure food safety. At the Food Safety and Inspection Service ( FSIS), the emphasis is on pre venting rather than detecting food borne contamination. Prevention is the best way to deal with drug abuse, and it is the best way to ensure food safety. To best prevent food safety problems, government, industry and consumers must acknowledge their respective responsibilities for ensuring safe food. The inspection services are becoming more science driven, and intend for their evaluation of biotechnology products to be based on sound science.

The Food Safety and Inspection Service is responsible for ensuring the safety and wholesomeness of meat and poultry. Last year, 121 million head of livestock, almost 5.9 billion birds, and 150 billion pounds of processed product were inspected. The Food Safety and Inspection Service is the agency that provides the final assurance that the meat and poultry products of biotechnology are safe. Some food safety responsibilities are shared with other agencies. In order to ensure that plans for new products are well coordinated, a Food A nimal Biotechnology Information Exchange Group has been organized. Representatives from USDA, which includes FSIS and the A nimal and Plant Health Inspection Service (APHIS); FDA 
which includes the Center for Veterinary Medicine and the Center for Food Safety and Applied Nutrition; and the Environmental Protection Agency (EPA ) meet regularly to consider jurisdictional issues and anticipate problems and concerns.

Bringing improved foods to market requires the scientific assurance of safety. Biotechnology products are expected to be safe, but that safety

\section{Biotechnology prod ucts are expected to be safe, but that safety must be dem onstrated and docu mented to ensure public health and to win public confi dence.}

must be demonstrated and documented to ensure public health and to win public confidence. At FSIS, animal products of biotechnology will be reviewed and approved under existing regulations. A formal position is currently being developed regarding how products of biotechnology that affect the meat and poultry industry will be reviewed and evaluated. The current position is based on technology as it is now, but the position will evolve over time to keep pace as new technology becomes available and as scientific findings point to the need for changes. We want our regulatory process for biotechnology to be a public one. Surprises do not do anyone any good. We cannot afford to operate behind closed doors with consumers questioning our actions or decisions. We intend to share our recommendations with USDA's A gricultural Biotechnology Research A dvisory Committee to ensure all scientific considerations have been taken into account. Scientific considerations are our number one priority.

Food safety decisions must be based on the best science available. Emotional and socioeconomic issues, while important, cannot play a role in determining the food safety of biotechnology products.

There are two main areas to review in the current thinking on evaluating the safety of biotechnology products for the meat and poultry industry: substances added to meat and poultry products, and transgenic animals that carry a desired gene.

Substances added to meat and poultry products With a biotechnologically-derived enzyme, flavoring or other food additive, FDA is the agency responsible for approving the products for safety. Once the products have been approved by FDA, a safety and efficacy evaluation will be conducted for the specific use of the product in meat and poultry products at defined concentrations and specific formulations. This secondary review certifies the substance as safe and effective in meat and poultry in its planned use and that it presents no nutritional or other concerns. 
Transgenic A nimals The safety assessment of transgenic animals should be conceptually very similar to the evaluation of traditional animals. Biotechnology merely provides methods for making well-understood and precise genetic changes. In most cases, the changes themselves will be modest, directed at health, disease prevention and nutritional quality. In fact, the precise nature of the genetic change is known with transgenic animals, directing the safety inquiry to the appropriate issues. Traditional breeding provides no such clues. Also, if the animal containing the desired genetic material is heal thy, it is very likely the animal will be safe to eat. Just as is the case with traditional animals, the health of the animal is an important indicator of its safety.

The safety eval uation of transgenic animals focuses on two topics: the genetic insert and the nature of the gene product. The genetic insert is the piece of DNA added to the genome of transgenic animals. Unless it is infectious, it is of no consequence. The DNA of ani-

We want our regula tory process for bio technology to be a public one. Surprises do not do anyone any good. mals and plants that are consumed is all part of the food.

Although the gene product must be examined carefully, the safety questions are not new. Genes produce proteins, the evaluation of which is not new. Genes produce proteins and the evaluation of proteins is a routine food safety consideration. The FDA will be consulted on animal drug and other pharmacological products, and EPA on gene products that have pesticidal activity. If the protein product is alleged to be identical to other proteins al ready in the diet, we will require data to support its identity. In all cases, we will use existing tolerances and safety considerations for gene products that have the same effect as traditionally produced drugs, pesticides or additives.

Should biotechnology provide new products for which there are no tolerances or safety guidelines, we will require the appropriate toxicity and pharmacokinetic data to ensure the safety of the product.

To summarize our regulatory plans, FS1S expects that once the safety of the gene product is established, transgenic animals are likely to require similar safety considerations as traditional animals.

The use of biotechnology is not al ways an appropriate trigger for oversight. However, the method of production should not beignored. As in the safety review of traditionally produced food additives, the safety assessment takes into account contaminants likely to result from the particular 
process. The same will be done with products of biotechnology. Plans for regulating biotechnology products will afford consumers the same high level of safety and confidence they have enjoyed for years. Science will drive FSIS decisions. Hopefully science will drive regulatory decisions worldwide.

Biotechnology is international in scope and it is imperative that its safety be judged with scientific standards. We intend to work with Codex and other international organizations such as the International Plant Protection Conference and the International Office of Epizootics to review international food standards as they relate to biotechnology. These groups can help coordinate scientific standards that ensure the food safety of biotechnology products. Harmonized food safety standards will help settle international disputes, reduce trade conflicts and improve consumer confidence.

Codex will hold a biotechnology consultation in N ovember, 1990, at which experts will discuss the food safety implications of biotechnology and will determine whether there are any food safety questions that cannot be handled by the current Codex organizational structure. The United States is also working with the European Community $(E C)$ to resolve food safety disputes. Secretary of Agriculture Clayton Yeutter and Under Secretary Richard Crowder met in early June with their counterparts from the Office of European Community Development. The Secretary has also set up regular consultations with the European Community's Director Generalship for Agriculture to discuss food safety. These forums should prove useful in discussing potential disputes early rather than waiting for conflicts to arise.

Biotechnology will see its share of conflict. It is a new technology that is entering the marketplace at a time when consumers are anxious about the use of technology in food production. Consumers want "natural" products that are free of synthetic additives. They also want nutritious, convenient, high quality, well-packaged foods-all of which require technology. Biotechnology will help give consumers what they want.

Biotechnology will help fight bacteria that contaminate food. Biotechnology can reduce the fat in meat products and add nutritional value to other products. A long road lies ahead in convincing the American public that technology and its use in food production is not bad, and FSIS is committed to helping consumers understand the role of technology-including biotechnology - in food production and safety. Biotechnology critics are 
poised to impugn food safety as a rallying point against the new technology. The government, along with the food and biotechnology industry, must use sound science to prove food safety and to stand behind our public health decisions. If emotions were allowed to overrule sound science, unjustified food safety scares are risked along with a total loss in consumer confidence. We would also be breaking our trust with the public, which expects us to do the right thing, even when it is difficult and controversial.

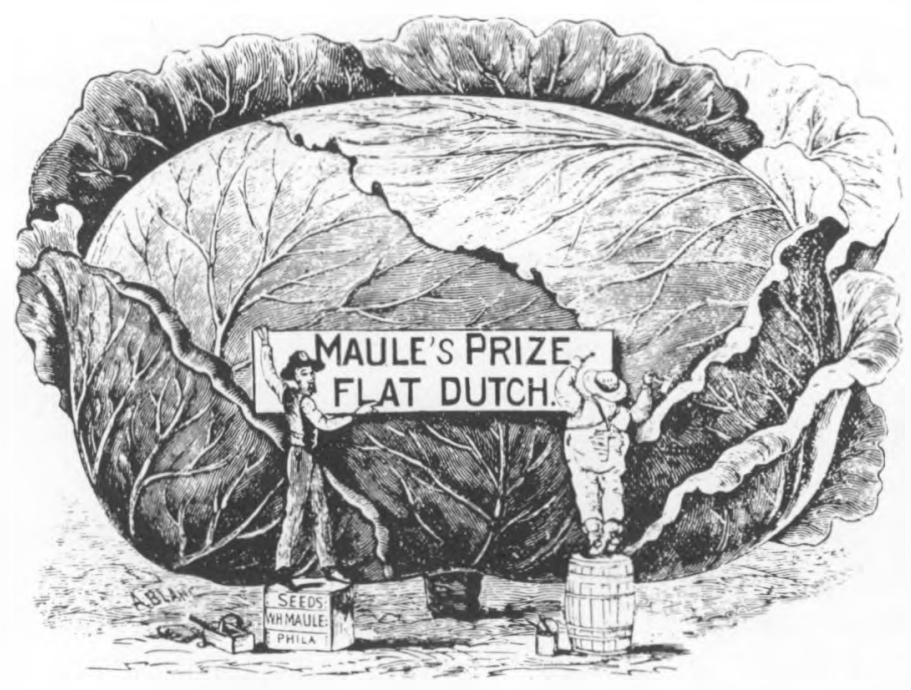

